\title{
Blending Projects Serving Public Education into Teacher Training
}

\author{
Márta Turcsányi-Szabó \\ ELTE University, Faculty of Informatics, \\ Informatics Methodology Group, TeaM Lab \\ 1117 Budapest, Pázmány Péter Sétány 1 C., Hungary \\ turcsanyine@ludens.elte.hu, \\ WWW home page: http://teamlabor.inf.elte.hu/
}

\begin{abstract}
About 10 years ago informatics teacher training did not seem to be too productive. Even though many students graduated, most of them chose well paid jobs as IT specialists rather than underpaid teacher positions in Hungary. What is then the reason for striving to provide the most up-to-date technology and methodology for future teachers who will never be able to transfer their gained knowledge into public education? The only possible solution seemed to be to convert to e-learning. The significance of TeaM elearning activities at ELTE University is mainly that they are interconnected and add up from course project works, undergraduate diploma works, Ph.D. dissertations of students, as well as all local and international projects that TeaM Lab participates in. Thus a dynamic development is under continuous progress which is a win-win relationship between all participants, teacher training and projects.
\end{abstract}

\section{Introduction}

It is believed that this century shall be the century of the information society. The Hungarian government set up its goals - development of information infrastructure, generalization of electronic information supply, educating citizens of the information society, stabilization of a competitive economy, efficient services, public administration and a human-centred society - several years ago. All of these goals themselves require the development and modernization of all levels in the education of the future informatics experts.

The Faculty of Informatics (http://www.inf.elte.hu/en) - one of the newest faculties in the Eötvös Loránd University (ELTE - http://www.elte.hu) - considers its main task the training of informatics experts and teachers as well cartographers 
and geoinformatical specialists. The aim of the informatics teacher major is to train teachers who can educate the disciplines of informatics within all levels of schooling. They should also be able to give advice on their use for teachers of other subjects, to be active in professional and social life and to advance in their studies throughout life [1].

The high level of the training of informatics experts and teachers is strongly expected from the society because the teachers play a significant role in forming the society's information culture. That is why students have to possess the most up to date pedagogical knowledge, to be confident in the use of IT tools, to be aware of digital learning tools and innovative teaching methods.

TeaM Lab has been established in the beginning of 1997 under the leadership of the author of this paper with founding membership of students, some of which are now assistant professors and have their own specialty in e-learning activities. TeaM Lab (Teaching with Multimedia) operates within the Informatics Methodology Group at the Faculty of Informatics and serves mainly informatics teacher training undergraduate and graduate programs. Its aim is the application, teaching, experimentation, evaluation, research and development of innovative multimedia tools and methodologies for the benefit of effective learning and developing skills. Research includes the ergonomics and content of developing educational applications, authoring tools, Internet and telematic environments, their crosscurricular and cultural integration, creative implementation and evaluation of their effects on the learning process. Our methods give emphasis to creative open ended explorations within constructive environments.

TeaM Lab takes an active part in local and international scientific life, which is realised within the spectrum of activities and publications, as well as our active participation in European Union projects. Our activities are not the sole work of our members, but we co-ordinate and integrate the work of our students (doing Ph.D. research and courses, dissertations, and undergraduate course assignments) as well as the work of our experimental schools' children and teachers. This TeaM-work is reflected in our web pages: http://teamlabor.inf.elte.hu/.

\section{TeaM e-Learning}

If one is working 25 years in teacher training, there must be times when doubts surface and remedies are sought for. About 10 years ago informatics teacher training did not seem to be too productive. Even though many students graduated, most of them chose well paid jobs as IT specialists rather than underpaid teacher positions. What is then the reason for striving to provide the most up-to-date technology and methodology for future teachers who will never be able to transfer their gained knowledge into public education? The only possible solution seemed to be to convert to e-learning:

- to provide infrastructure and environment for learning and teaching with technology; to be able to actively contribute even if students cannot be physically present, which could prolong their contribution after graduation; 
- to convert as many courses as possible to productive project work serving public education; to get value out of innovative knowledge gained by students while at university and give meaning and context to their contributions by directly placing them into learning situations;

- to involve students in all our local, EU and other international e-learning activities, projects, and research; to develop competencies in working in team on international level and quality;

- to provide free access to projects and products for public education; to gain a short-cut for directly transferring innovation into public education;

- to maintain tele-mentoring services (apart from learning about telementoring) as course work; to provide direct help for public education and alternative learning institutions in implementing innovation.

Thus we can say that public education already gains from students' active participation while at university and a lot of the students become highly motivated in further involvement with e-learning activities after experiencing the success of their own contributions.

\section{TeaM courses}

Most of our courses are undergraduate non-compulsory electives, mainly within the informatics teacher training program and secondly for programmer and program designer mathematicians. With relation to developing e-learning materials and running projects in public education, we here restrict our description to subjects closely related within special M.S. and Ph.D. studies that contribute to the production of materials and services for newly launched projects.

Table 1. Course blocks offered on M.S. and Ph.D. level building spirally on each other

\begin{tabular}{lll} 
MSc & \multicolumn{1}{c}{ Autumn semester } & \multicolumn{1}{c}{ Spring semester } \\
C. & \multicolumn{1}{c}{ Evaluation of educational softwa } \\
& ICT in basic education & Designing educational microwor \\
& Authoring tools in basic education & \\
H. & & Desktop publishing \\
& Web design & Web animation \\
& & Designing multimedia materials
\end{tabular}

B. Tele-mentoring I. Tele-mentoring II.

Ph.D. 1 Research methodology

Ph.D. 2 Innovative, capacity building digital pedagogy
Foundations of ICT and types of interactions

Inquiries on e-Learning 
Each course has a specific content and output requiring collaborative project work as contribution to an emerging project:

- Evaluation of educational software: Formative evaluation of educational software in accordance with the evaluation rubrics developed throughout the years. Analysis of National Curriculum and teaching strategies in order to define a hypothesis for pinpointing the scope of development, designing activity to produce the process, and composing pre- and post-test to prove hypothesis. We often use educational microworlds and portals for evaluation that have been developed by our students in previous semesters or are parts of running projects.

- ICT in basic education: Analysis and methodological evaluation of ICT use in the full scope of kindergarten, elementary and lower secondary education. Designing collaborative e-learning projects for launch in the coming semester.

- Authoring tools in basic education: For many years we used Comenius Logo, but since 2001 we use the Imagine authoring tool. Students develop modelling assignments for different disciplines practicing constructivist pedagogy. The e-learning material of the course itself has been improved, updated and refined from the feedback of this process. The course runs blended, using the e-learning course material individually plus consultation periods in class.

- Designing educational microworlds: For many years we used Comenius Logo, but since 2001 we use Imagine as the authoring tool. Students develop complex educational microworlds to be used in different disciplines practicing experiential and constructivist pedagogy. Our microworlds within e-learning materials have been improved, increased and refined as products of this course.

- Desktop Publishing: Mastering all aspects of design criteria for development of printed learning materials and analysis of different prints on the process of perception and understanding. Designing printed materials for different educational purposes.

- Web design: Mastering all aspects of web design and analysis of different web sites on navigation, and usability. Designing web sites for different educational purposes. Course can be registered only as distance education plus consultation periods.

- Web animation: Mastering all aspects of web animation for use in web sites and simulation programs and analysis of different previous products on process of perception and understanding. Designing web animations for different educational purposes. Course can be registered only as distance education plus consultation periods.

- Designing multimedia materials: Mastering all aspects of design criteria for development of e-learning materials and analysis of learning environments and learning styles of students. Students participate in experiments on the effects of different learning materials to the learning process. Designing e-learning materials to be integrated into one of the portals under development. 
- Tele-mentoring (2 semester course): Study of different aspects of distance and e-learning, different frame systems used and the role of mentors in virtual learning. Analysis of previous e-learning projects. In parallel, students register with an ongoing e-learning project, and take part live in the mentoring process. The course can be registered only as distance education plus consultation periods - using different e-learning environments.

There are also some postgraduate $\mathrm{PhD}$ courses in connection to undergraduate courses:

- Research methodology: Study of research methods and the different situations that suit their application. Studies in writing up a research paper - students have to produce research plans for future projects.

- Foundations of ICT and types of interactions: Research on foundations of technology in education, the types of interactions that are involved and the methodologies used - students have to produce monographs of their research field.

- Innovative, capacity building digital pedagogy: Research on innovative technology, tools and methods as well as reports on their research results concerning effective use within the learning process. Students take part in upgrading evaluation rubrics for Evaluation of educational software course and design criteria for Designing educational microworlds course. Students develop evaluation instruments for use within e-learning projects.

- Inquiries on e-learning: Study of action research "theory research- data collection \& analysis - evaluation" cycle and its implementation into practice through a live e-learning project. Students have to produce evaluation reports of projects.

\section{TeaM activities}

All courses require project work that outlines a definitive part of an actual project to be launched and the sequence of courses contribute to the building, launching, running and evaluating processes within project activities.

Table 2. Blending course deliverables into project work

$\begin{array}{cccc}\text { Sept. Oct. Nov, Dec. } & \text { Jan. } & \text { Feb. } & \text { Mar. Apr. May } \\ \text { ICT in basic education } & & \text { Designing multimedia e-learning } \\ \text { Brainstorming } & & \text { materials } \\ & & \text { Development of materials } \\ \text { Foundations of ICT and types of } & & \text { Innovative, capacity building digital } \\ \text { interactions } & \text { pedagogy } \\ \text { Planning research } & & \text { Research }\end{array}$

Tele-mentoring I., II.

Projects are launched in February and end at end of May

Inquiries on e-learning

Evaluation of educational materials 
Projects are launched directly into public education, often in association with the John von Neumann Computer Society Public Education SIG, and results are reported twice a year at conferences of the Association of Informatics Teachers, where discussions with practicing teachers can produce important conclusions for the future. Some of these projects were run within local or European funded activities. Thus in the past 10 years or so, TeaM managed to run lots of projects within public education and has contributed to public education considerably by injecting innovation in a direct way, through projects blended into the TT program. Some specific projects of the past years:

ELTE kindergarten project: For more than 20 years we have constantly supervised the university kindergarten and developing educational software for early education. The project is continuously mentored on spot by our students $[2,3]$ (project web page: http://matchsz.inf.elte.hu/colabs/nursery/index.html).

„MATCh" Multimedia Authoring Tool for Children EU project: Developing a multimedia authoring system for children, story applications and its implementation within Fogócska elementary school $3^{\text {rd }}$ grade between 01.01 .1997 and 01.01 .1999 [4] (project web page: http://comlogo.web.elte.hu/team/match/).

Tele-house projects: Developing a model for mentoring youth (aged mainly between 10 and 14) living in underdeveloped regions and giving them a perspective for their further development. The first project involving the least developed areas of Hungary was 01.12.2000-30.07.2001, sponsored by US AID, and the second project involving various other regions was 01.09.2001-15.01.2002, coordinated by Demnet and sponsored by the Informatics Committee of the Prime Minister's Office $[5,6,7,8,9]$. These tele-house projects were the first such in Hungary that provided a model for capacity building activities in underdeveloped regions and had a great impact for further tele-house activities. Such activities are now well implemented within the Tele-house association (http://www.telefalu.hu/g), where lots of e-learning activities emerge by now as well as IT mentoring (project web page - only in Hungarian - http://matchsz.inf.elte.hu/Telehaz/).

"Co-didactics" Austrian-Hungarian project: Joined teacher-training activities in research and development of creative didactic tools that could be implemented, in both cultural settings, sponsored by Hungarian Science and Technology Foundation between 01.01.2001 and 31.12.2002 [10] (project web page: http://matchsz.inf.elte.hu/tet/).

TeaM perspective project: Building a model for practical teacher training, producing basis of the needs of teachers/mentors, providing competencies in developing effective tools for progress within their dynamically evolving role, transferring innovation into public education by meeting the notion and the requirements of present age in public education - sponsored by Pubic Funds for Modernisation of Public Education (project web page - only in Hungarian http://matchsz.inf.elte.hu/koma/).

TeaM Challenge game series: Providing examples for context based "e-problem solving", developing key competencies through search for solutions of complex problems, data analysis and synthesis using the Internet and various application 
systems within interdisciplinary topics through team project work among students aged 10-14. In 2001 it was developed under course project work that was redeveloped by students and played in 2002. In 2003 it was a huge national game that was developed for the $100^{\text {th }}$ anniversary of John von Neumann and sponsored by several institutions, among others the Ministry of Education, and was a tremendous success. In 2004 we switched environment and the game was sponsored by IBM and Pubic Funds for Modernisation of Public Education. In 2005 we opened up for more contributions coming from schools and are sponsored by the John von Neumann Computer Society, Public Education SIG [11] (project web page - only in Hungarian - http://matchsz.inf.elte.hu/Kihivas/).

NETLogo users circle project: Development of students' main competencies (aged 10-14) by involving future teachers, practicing teachers as mentors. The used e-learning material has been dynamically evolving (through the past 15 years through course work) and is now more than 1500 pages. The material contains microworlds for use within different disciplines of public education, illustrating modes of development and configuration, and developing competencies for modelling in different disciplines both for elementary and teacher education. The project is open to all schools, homes and entities and is continuously mentored by our students. The project has been sponsored by the NETLogo EU project (for producing an English version) and Pubic Funds for Modernisation of Public Education for operating users circle [12] (project web page - only in Hungarian http://kihivas.inf.elte.hu/halogo).

"Colabs" Minerva project: To find ways to support children in building and testing models collaboratively across European cultures and beyond. Objectives are to provide infrastructure for collaborative work; to provide answers for guiding research questions: with whom, how and what kinds of knowledge should children learn at a distance and how best can they be supported in this learning; and to develop learning tools that can be transferable into other domains using the Imagine authoring system. The project was coordinated by the head of the TeaM Lab and not only ELTE students, but students from other universities also participated between 01.10.2002 and31.1.2005 (project web page: http://matchsz.inf.elte.hu/colabs/).

The project developed quite a few products that have already been commercialised or are on their way, those involving mostly our students are:

- Hungarian localized version of Imagine authoring tool [http://logo.sulinet.hu/]

- "Digital Literacy" e-learning course for children ages 9-16 - only in Hungarian - [http://sdt.sulinet.hu/])

- "Creative Classroom" CD published by Logotron in UK [http://www.logo.com/cat/view/creative_classroom.html]

In addition, some further portals have been developed and operated for research:

- Logo Arts portal: Familiarising children with modelling structures resembling contemporary art, thus drawing parallel between works of artists and mathematics modelling using the Logo programming language (portal only in Hungarian - http://team1.inf.elte.hu/art).

- Telling you in pictures portal: The project provides environment for collaborative and creative communication between groups of children from different language cultures of average age about 9-10 through different visual 
assignments and creative tools (portal: http://matchsz.inf.elte.hu/colabs/colaboratories/portal/pict_com.htm).

"Kaleidoscope" Network of Excellence: Integrating existing research to develop new concepts and methodologies from a multidisciplinary and cross-cultural perspective. Ph.D and diploma students of TeaM Lab were so far involved in Joint Research Projects for: Personalised and Collaborative Trails of Digital and NonDigital Learning Objects; Interaction between learner's internal and external representations in multimedia environment; Building Visual Interactive Blocks for Tangible Mathematics 01.01.2004-31.12.2007 (project web page: http://wwwkaleidoscope.imag.fr/pub).

TAMI projects: The Neural Information processing Group and TeaM Lab have been involved in common research activities with the AAC foundation (Augmentative and Alternative Communication and Methodology Center) since 2003. The aim of the research is to find alternative hardware and software solutions for communication and further development for children and youth seeking help from AAC services (project web page: http://nipglab17.inf.elte.hu:8180/portal/servlet/Main).

Special education projects: TeaM Lab also has a long term R\&D cooperation since 2003 with Bárczi Gusztáv Faculty of Special Education and with its connected centres for fieldwork in which we develop software tools for problematic children to aid their development in different fields. Our future teachers take part in developing software tools and visit schools to monitor results.

Capacity building developmental software project: TeaM Lab also has an ongoing development with the Hungarian Academy of Sciences Psychology Research Institute Psychophysiology Group developing diagnostic and developmental software tools for children with dyscalculia syndromes. Software development is part of course projects.

\section{Conclusion}

The significance of TeaM e-learning activities is mainly that they are interconnected and add up from course project work, undergraduate diploma work and $\mathrm{PhD}$ dissertations of students, as well as all local and international projects that TeaM Lab participates in. Thus a dynamic development is under continuous progress which is a win-win relationship between all participants, teacher training and projects.

Students experience and master innovative technology and methodologies, contribute with their own developments through active participation in an ongoing project, which are then directly implemented and mentored within public education. These ongoing e-learning projects transfer innovation into public education with a short cut, which is then evaluated through research analysis involving $\mathrm{PhD}$ students to gain further knowledge for future projects and developments.

Our teacher trainers not only train future teachers, but also develop mentors who can then give aid to local helpers at schools, other educational establishments involving children's activities, or parents at home, both locally and internationally. 


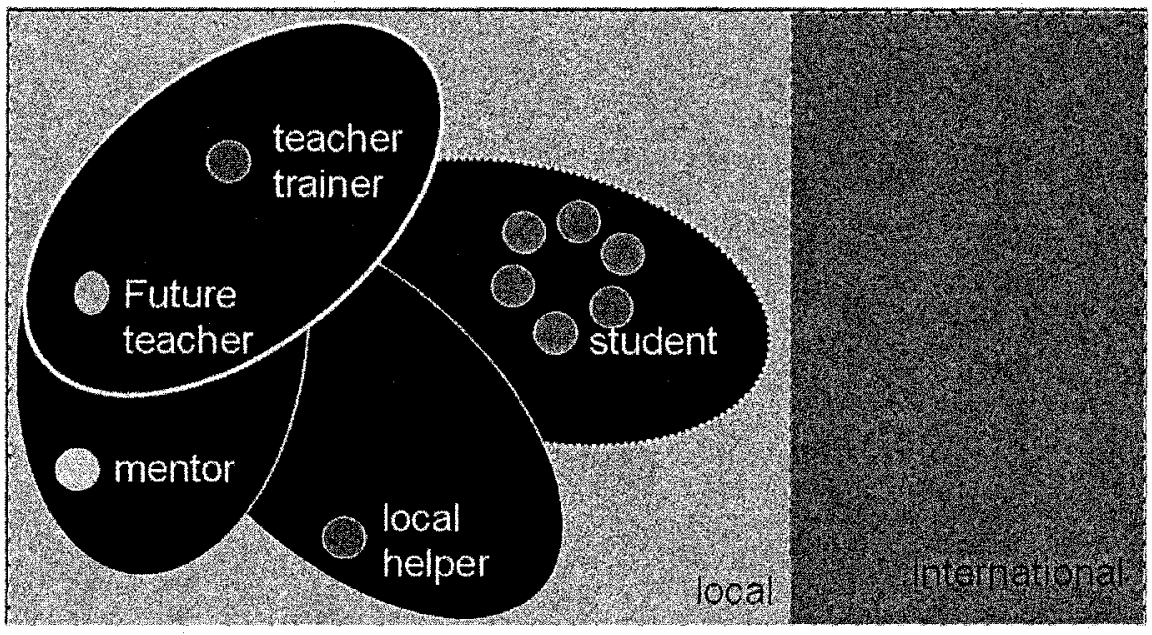

Figure 3. Our e-Learning model in the past 10 years

Our results are quite positive:

- Student teachers concentrate now more on children and their needs than the power of computer itself (even though their interests were mainly in that direction).

- Project assignments require strong connection to the National Curriculum, which is thus examined thoroughly in practical terms too.

- Student teachers must engage in the synthesis of their mastered knowledge when designing environments, microworlds and educational materials to suit needs of teachers and be able to create configurable tools to adjust to the differences of pupils.

- Project work submitted by future teachers is actually evaluated by pupils themselves, thus student teachers tend to produce higher quality work, as they are more afraid of this open evaluation than that of their trainers.

- Future teachers are able to set up empirical evaluations of educational tools that could give more exact values of purchased products.

- Future teachers are able to recognize value in all types of tools that can be used in a broad spectrum of school subjects, thus they are able to give advice to other staff members teaching different disciplines.

- Project work submitted by student teachers is more valuable, as they are able to judge more easily and filter weak points of microworlds or educational materials.

- Most of all, student teachers enjoy their studies much better and are willing to contribute more than before, since they are assured that their quality work is not just laid aside in drawers, but actually is used in effective school work to which they are proud to contribute. 


\section{References}

1. Informatics Methodology Group: Informatics teacher training program http://teamlabor.inf.elte.hu/_teamfiles/review/info_teacher.pdf

2. Turcsanyi-Szabo, M. (1997). Approaching Arts Through Logo, in Proceedings of the Sixth European Logo Conference, pp. 284-294. John von Neumann Computer Society, Budapest, Hungary. http://caesar.elte.hu/ eurologo/lectures/papartj.htm

3. Turcsanyi-Szabo, M. (1997). Designing Logo Pedagogy for Elementary Education, in Proceedings of the Sixth European Logo Conference 1997, pp. 273-283. John von Neumann Computer Society, Budapest, Hungary. http://caesar.elte.hu/ eurologo/lectures/papthij.htm

4. Triantafilou, S., Pixton, J., Kallenbach, K., Kalas, I., Turcsanyi-Szabo, M., Pintelas, P., Nikolova, 1. (1997). MATCh: a Multimedia Authoring environmenT for Children (an INCO-Copernicus European Community Program), in Proceedings of the Sixth European Logo Conference, pp. 80-84. John von Neumann Computer Society, Budapest, Hungary. http://eurologo.web.elte.hu/lectures/match.htm

5. Turcsanyi-Szabo, M. (2002). Learning in tele-houses - a perspective for development in underdeveloped regions within Hungary

http://www.infovek.sk/konferencia/2001/zbornik/turcsanyi.html

6. Turcsanyi-Szabo, M. (2002). Capacity building in tele-houses - a model for telementoring, Proceedings of IFIP WG 3.5 Working Conference: Learning with Technologies in School, Home and Community, Manchester.

7. Turcsanyi-Szabo, M. (2003). Capacity building in tele-houses: A model for telementoring, ed. Marshall G., Katz, Y. Learning in School, Home and Community, pp 101111, Klewer Academic Publishers.

8. Turcsanyi-Szabo, M. (2003). Practical Teacher Training Through Implementation of Capacity Building Internet Projects, Proceedings of SITE 2003. http://dl.aace.org/12001 The paper was published and presented as invited presentation at SITE 2003, nominated for "Best Practice" award.

9. Turcsanyi-Szabo, M. (2004). Informatics teacher training in Hungary: building community and capacity with tele-houses, ed. A., Brown \& N., Davis, World Yearbook of Education 2004: Digital Technology, Communities \& Education, RoutledgeFalmer

10. Turcsanyi-Szabo, M., Pluhár, Zs., Neuwirth, E. (2001). Extending the boundaries of teacher education with Co-didactics, Proceedings of Eurologo2001 Conference, pp. 106112, Linz, Austria.

http://www.ocg.at/activities/books/volumes/band\%20156/KNeuwirthTurcsanyiPluhar.do c

11. Réthely-Prikkel, B., Turcsanyi-Szabo, M. (2003). Team Challenge, Proceedings of Eurologo 2003, pp. 281 - 290, 27-30 August Porto, Portugal. http://matchsz.inf.elte.hu/Colabs/Porto/pubs/RPB_TSzM.pdf

12. Turcsanyi-Szabo, M. (2001). Why S.O.M.E. Logo Environments are Suitable for Broader Educational Purposes?, in Proceedings of Eurologo 2001 Conference, pp. 97-106, Linz, Austria. http://www.ocg.at/activities/books/volumes/band\%20156/K61 Szabo.zip 